\title{
Optimization of production process of manufacturing parts using simulation modeling of aperture
}

\author{
Revina I V \\ Omsk State Technical University \\ Omsk, Russian Federation \\ e-mail: revina_i@rambler.ru
}

\author{
Boyarkin G N \\ Omsk State Technical University \\ Omsk, Russian Federation \\ e-mail: revina_i@rambler.ru
}

\begin{abstract}
The article considers the model of the technological line operation for parts manufacturing, made in the simulation system Arena Rockwell. The relevance of the study is to reveal the "bottlenecks" and to answer a "what if" question when considering different models. Optimization parameters are the maximum possible number of parts manufactured and the maximum load of equipment, i.e. maximizing profit. Reject rates and parts reworking are considered to be limitations. As a result of modeling, having considered various models of the production process organization, the following was established: the machines load, the number of parts produced, the average length of parts in the production process, the average number of parts in the queue, profits and losses in the production process. The obtained results of simulating will organize an economically justified production process - two-point production line with a 1.45 timeincrease in profit.
\end{abstract}

Keywords - production system, simulation model, simulation moderation, production organization

\section{INTRODUCTION}

The production process of parts manufacturing is a complex system consisting of many separate elements and relationships arising in the production process. The state of the process is characterized with such parameters as time, cost, equipment loading, etc. The course of the technological process is influenced by various production factors that lead to changes in the technological process course.

With the computer technology development, simulation modeling has become the most used tool for simulating.

Simulation modeling is a process of developing a real system model and setting up experiments on this model to understand the behavior of the system within the limits imposed [1]. The simulation has a number of advantages:

- new designs, layouts can be tested without using resources to their implementation;

- we can consider the behavior of the simulated system in a certain time interval (per day, year, etc.), and it will assess the prospects for the development of the system;
- variability of production conditions can be considered to identify bottlenecks ("places of decline in productivity", downtime of equipment, etc.) and to answer "what if" questions. This will reveal which factors are the determining factors in the behavior of the system being simulated [2].

Real world events are complex and uncertain. Therefore, it is necessary to develop models that consider the world diversity (deterministic and stochastic models, discrete and continuous models, static and dynamic models). Simulation modeling allows doing it.

Currently, simulation modeling is used in modeling of production processes $[3,4,5]$, transportation [6], warehousing [7], in construction [8], economics [9] and operation of technical systems [10], etc.

The production process of manufacturing a part is a complex system consisting of many separate elements and relationships arising in the production process. When using simulation, the maximum possible reproduction of the production situation has been achieved. Consideration of the production conditions multivariance allows one to identify "bottlenecks" and to answer "what if" question.

For enterprises with a rapidly changing range of goods and small series production output, the following tasks are relevant: the rational use of equipment, a working time fund, forms of the production process organization, time estimates of the cyclical turnaround, size of stocks and storage facilities capacity. Under these conditions, the value (relevance) of decisions made increases with the reduction of time spent on decision making. Therefore, simulation modeling is an effective tool for solving a wide range of production problems.

The subject study is a well-grounded choice of an effective form of the production process organization. Optimization parameters are the maximum possible number of parts manufactured and the maximum load of equipment, i.e. maximizing profit. Reject rates and parts reworking are considered to be limitations. 


\section{PROCESS DESCRIPTION AND DATA MODELLING}

The production process is manufacture of metalworking machines and consists of six stages. Parts are processed after their quality being evaluated with the controller and the time interval is $9.5 \pm 2.5$ minutes. Consistent movement of parts during operations is carried out in the production process. Transfer from one operation to another is executed one by one (due to the details of the part). During their processing, the sequence of stages should be clearly observed. Stages replacement is not allowed. Each stage uses one piece of equipment. The processing time for stages is shown in Table 1.

TABLE I. CHARACTERISTICS OF THE PRODUCTION PROCESS

\begin{tabular}{|l|l|l|}
\hline \multirow{2}{*}{$\begin{array}{c}\text { The stage } \\
\text { number }\end{array}$} & \multicolumn{2}{|c|}{\begin{tabular}{c} 
Part processing time on the machine \\
\cline { 2 - 4 } min
\end{tabular}} \\
\hline 1 & 12 & $\begin{array}{c}\text { Maximum, } \\
\text { min }\end{array}$ \\
\hline 2 & 5 & 6 \\
\hline 3 & 3 & 5 \\
\hline 4 & 4 & 5 \\
\hline 5 & 6 & 8 \\
\hline 6 & 9 & 12 \\
\hline
\end{tabular}

After processing (all stages have been completed), the part is moved to the controller, and it assesses its quality and gives an opinion on the conformity of the part to the requirements.

In the developed model, there will be assessed economic parameters when implementing the production process of parts manufacturing - losses due to machine downtime and profit for the processing of parts. Table 2 shows the parameters of profit (loss) per hour for all machines.

TABLE II. ECONOMIC PARAMETERS OF THE EQUIPMENT USED

\begin{tabular}{|l|l|l|}
\hline $\begin{array}{c}\text { Machine } \\
\text { number }\end{array}$ & $\begin{array}{c}\text { Profit for processing } \\
\text { parts, \$/h }\end{array}$ & $\begin{array}{c}\text { Losses due to } \\
\text { downtime, \$/h }\end{array}$ \\
\hline Machine 1 & $50 \quad$ & 20 \\
\hline Machine 2 & 30 & 10 \\
\hline Machine 3 & 25 & 8 \\
\hline Machine 4 & 35 & 12 \\
\hline Machine 5 & 40 & 10 \\
\hline Machine 6 & 30 & \multicolumn{2}{|l}{} \\
\hline
\end{tabular}

Profit on the production process is defined as:

$$
C=C_{w}-C_{p}
$$

where $\mathrm{C}_{\mathrm{w}}$ is the total profit for processing parts on all machines determined by the hourly rate and operating time for each machine, $C_{p}$ is total losses due to machine downtime determined by the hourly rate and idle time for each machine.
To determine the workload of machines for various uses is possible when using simulation modeling.

To achieve this goal, several stages of modeling will be performed (simulation modeling of the production process is carried out for 1 shift ( 8 hours)):

1. We will develop the simulation model of "AS-IS" process. The model will determine the following parameters: the number of parts processed by each machine in 8 hours; workload of machine tools; losses due to machine downtime; profit for processing parts on machine tools; average length of parts stay in the production process; the average number of parts in the processing queue for a particular machine; average length of parts stay in the processing queue. (These parameters will be evaluated at all stages).

2. Let us change the model "AS-IS" considering the limitations - defective parts are $20 \%$; the possibility of reworking defective parts.

3. "Bottlenecks" for the "AS-IS" model will be defined.

4. The simulation model "TO-BE" will be developed, and it realizes:

- possibility of inefficiently used machines additional loading;

or

- possibility to install additional equipment on the "bottlenecks."

5. The optimal model "TO-BE" has been chosen.

Currently, the software products market is represented with a sufficient number of simulation tools. The following systems are the most popular: Arena Rockwell, AnyLogic, Simio, Simul, Repast, NetLogo, FlexSim, Ponodel. Arena Rockwell software product for simulation is used in this article.

Arena Rockwell is distinguished by its wide functionality, ease use, a rich set of statistical indicators, and it includes dynamic animation [11].

\section{SIMULATION MODEL DESCRIPTION AND DATA MODELLING}

The model "AS-IS" is shown in Fig. 1 (Stage 1 of modeling). The Create 1 ("Create") module is used to generate the part income ("Part 1"). Modules OP 1 - OP 6 ("Process") simulate the process of processing parts in the corresponding stages. Dispose 1 ("Dispose") module brings the processed parts out from the production process.

The model "AS-IS" with the possibility of defective parts reworking is shown in Fig. 2. By condition, defective parts can have only one reworking. If the defect is not eliminated after it, the part is Pentolyed From the (p)oductioh) process. "Decide 1 ("Decide") module" specifies "2-way by Chance" - $80 \%$ (defective parts are 20\%). Assign 1 ("Assign") "marks" the defective parts being processed, and assigns them number 1 . "Decide 2 module" ("Decide") tracks the cycles for defective parts processing and outputs the parts from the production process. 
The model "TO-BE" is shown in Fig. 3. The machines are underloaded at stages OP 2 - OP 4. Therefore, the option of additional equipment loading by processing another part ("Part $2 ")$ is considered. The processing time of "Part 2" in OP 2 OP 4 stages is equal to "Part 1" processing time. "Create 2 ("Create") module" is used to generate "Part 2" income. "Decide 3 module" ("Decide") allows one to define "Part 1" or "Part 2". "Part 1" continues the subsequent processing in OP 5 and OP 6 stages, "Part 2" outputs from the processing process using "Dispose 2 module" ("Dispose").

\section{RESULTS AND DISCUSSION}

The results of simulation modeling when implementing the model shown in Fig. 1 are generated in the simulation results report ("Resources", "Queues", "Entities" panes) and they are shown in Fig. 4.
The report shows uneven loading of machines from the load factor 1.00 for Machine 1 (maximum load) to the load factor 0.30 for Machine 3 (maximum load). During 8 hours, 35 parts were completely processed, and 52 parts entered the production process. Therefore, the average wait time of parts in the drives before OP1 operation was 65.0447 minutes, and the average number of parts in the queue was 6.9500. The average length of the parts' stay in the production process was 102.56 minutes.

For this model, the total profit for processing parts on all machines was \$ 995.81 and losses due to machine downtime were $\$ 201.43$. Thus, the profit on the production process (according to formula 1) was $\$ 794.38$.

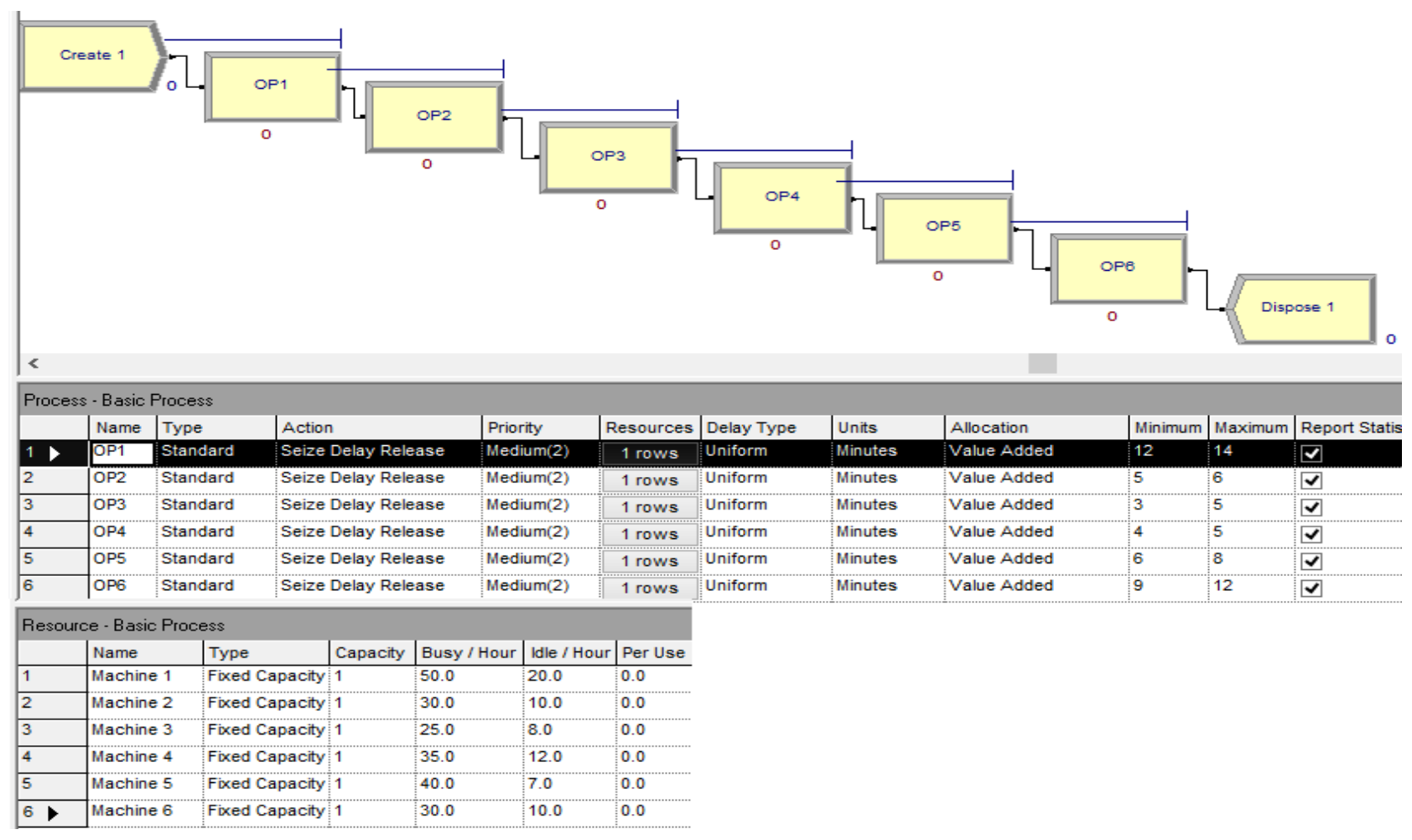

Fig. 1. Model "AS-IS" (Stage 1 of the simulation)

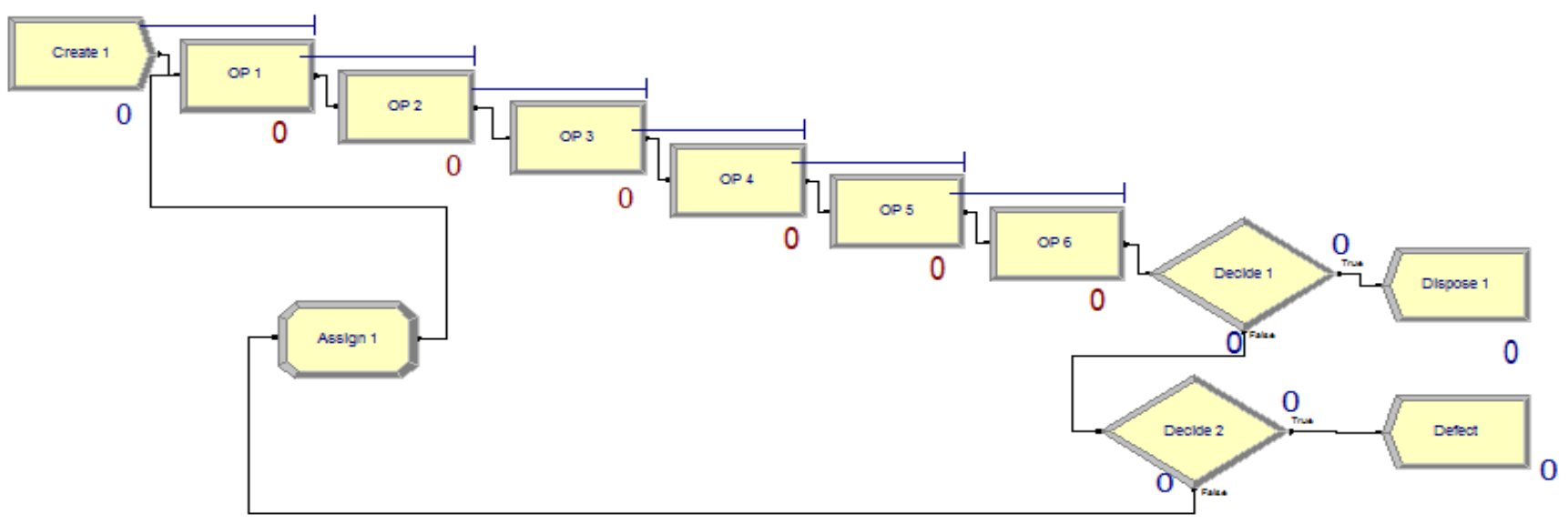


Fig. 2. Model "AS-IS" with the possibility of defective parts reworking (Stage 2 of the simulation)

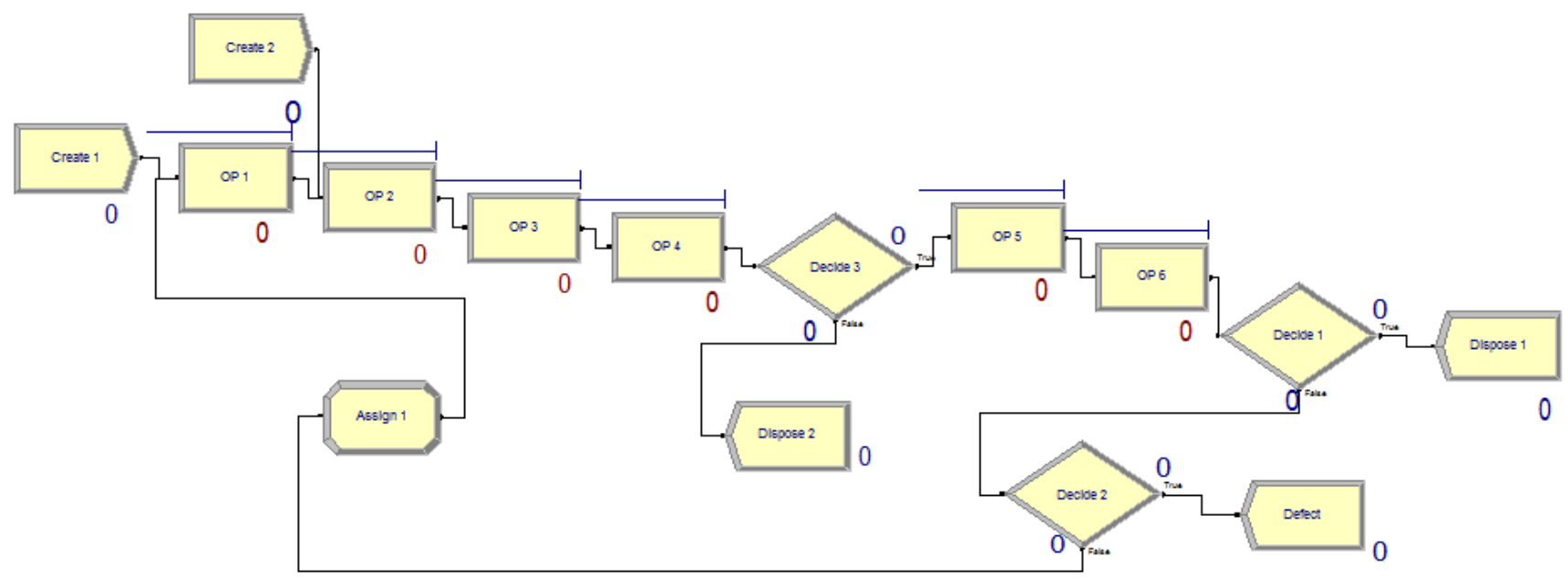

Fig. 3. "TO-BE" Model (Stage 4 of the simulation)

\begin{tabular}{|c|c|c|c|c|c|}
\hline & Inst Util & Num Busy & Num Sched & Num Seized & \\
\hline $\begin{array}{l}\text { Machine } 1 \\
\text { Machine } 2 \\
\text { Machine } 3 \\
\text { Machine } 4 \\
\text { Machine } 5 \\
\text { Machine } 6\end{array}$ & $\begin{array}{l}1,00 \\
0,42 \\
0,30 \\
0,34 \\
0,51 \\
0,76\end{array}$ & $\begin{array}{l}1,00 \\
0,42 \\
0,30 \\
0,34 \\
0,51 \\
0,76\end{array}$ & $\begin{array}{l}1,00 \\
1,00 \\
1,00 \\
1,00 \\
1,00 \\
1,00\end{array}$ & $\begin{array}{l}38,00 \\
37,00 \\
36,00 \\
36,00 \\
35,00 \\
35,00\end{array}$ & \\
\hline \multicolumn{6}{|l|}{ Cost } \\
\hline $\begin{array}{l}\text { Machine } 1 \\
\text { Machine } 2 \\
\text { Machine } 3 \\
\text { Machine } 4 \\
\text { Machine } 5 \\
\text { Machine } 6\end{array}$ & & $\begin{array}{r}\text { Busy Cost } \\
399.87 \\
99.54 \\
60.47 \\
92.88 \\
164.48 \\
178.57\end{array}$ & $\begin{array}{r}\text { Idle } \\
4 \\
4 \\
6 \\
2 \\
1\end{array}$ & $\begin{array}{r}\text { Cost } \\
0.00 \\
46.80 \\
44.65 \\
63.53 \\
27.22 \\
19.23\end{array}$ & \\
\hline Time & \multicolumn{5}{|c|}{ Other } \\
\hline Waiting Time & \multicolumn{4}{|c|}{ Number Waiting } & Average \\
\hline OP1.Queue & & 65.0447 & \multicolumn{2}{|l|}{ OP1.Queue } & 6.9500 \\
\hline OP2.Queue & & 0.00 & \multicolumn{2}{|l|}{ OP2.Queue } & 0.00 \\
\hline OP3.Queue & & 0.00 & \multicolumn{2}{|l|}{ OP3.Queue } & 0.00 \\
\hline OP4.Queue & & 0.00 & \multicolumn{2}{|l|}{ OP4.Queue } & 0.00 \\
\hline OP5.Queue & & 0.00 & \multicolumn{2}{|l|}{ OP5.Queue } & 0.00 \\
\hline OP6.Queue & & 0.04444914 & \multicolumn{2}{|l|}{ OP6.Queue } & 0.00324108 \\
\hline Total Time & & Average & Half Width & $\begin{array}{c}\begin{array}{c}\text { Minimum } \\
\text { Value }\end{array} \\
\end{array}$ & $\begin{array}{l}\text { Maximum } \\
\text { Value }\end{array}$ \\
\hline Part 1 & & 102.56 & (Insufficient) & 44.1918 & 163.95 \\
\hline
\end{tabular}

Fig. 4. Model report "AS-IS" (1st stage of modeling)

The implementation of the model, shown in Fig. 2, generated the report presented in Fig. 5. Reprocessing of defected parts increased the average length of the parts' stay in the production process to 117.17 minutes. The average waiting time for parts in the drives before OP1 operation increased to 75.0937 minutes, and the average number of items in the queue increased to 8.5314 minutes. There are 28 valid parts at the output of this model, 6 parts were re-processed, 1 detail has an unrecoverable defect (the results are not included in the reporting Fig. 5). Profit on the production process (according

\begin{tabular}{|c|c|c|c|c|c|}
\hline & $\underline{\text { Inst Util }}$ & $\underline{\text { Num Busy }}$ & Num Sched & $\underline{\text { Num Seized }}$ & \\
\hline $\begin{array}{l}\text { Machine } 1 \\
\text { Machine } 2 \\
\text { Machine } 3 \\
\text { Machine } 4 \\
\text { Machine } 5 \\
\text { Machine } 6\end{array}$ & $\begin{array}{l}1,00 \\
0,42 \\
0,31 \\
0,34 \\
0,51 \\
0,79\end{array}$ & $\begin{array}{l}1,00 \\
0,42 \\
0,31 \\
0,34 \\
0,51 \\
0,79\end{array}$ & $\begin{array}{r}1,00 \\
1,00 \\
1,00 \\
1,00 \\
1,00 \\
1,00\end{array}$ & $\begin{array}{l}38,00 \\
37,00 \\
36,00 \\
36,00 \\
36,00 \\
35,00\end{array}$ & \\
\hline \multicolumn{6}{|l|}{ Cost } \\
\hline $\begin{array}{l}\text { Machine } 1 \\
\text { Machine } 2 \\
\text { Machine } 3 \\
\text { Machine } 4 \\
\text { Machine } 5 \\
\text { Machine } 6\end{array}$ & & $\begin{array}{r}\text { Busy Cost } \\
397.67 \\
98.76 \\
62.43 \\
94.17 \\
164.00 \\
184.16\end{array}$ & $\begin{array}{r}\text { Idle } \\
\\
4 \\
4 \\
6 \\
2 \\
1\end{array}$ & $\begin{array}{l}\frac{\text { Cost }}{0.00} \\
16.62 \\
14.02 \\
63.71 \\
27.23 \\
17.18\end{array}$ & \\
\hline Time & \multicolumn{5}{|c|}{ Other } \\
\hline Waiting Time & \multicolumn{4}{|c|}{ Number Waiting } & Average \\
\hline OP1.Queue & & 75.0937 & \multicolumn{2}{|l|}{ OP1.Queue } & 8.5314 \\
\hline OP2.Queue & & 0.00 & \multicolumn{2}{|l|}{ OP2. Queue } & 0.00 \\
\hline OP3.Queue & & 0.00 & \multicolumn{2}{|l|}{ OP3.Queue } & 0.00 \\
\hline OP4.Queue & & 0.00 & \multicolumn{2}{|l|}{ OP4.Queue } & 0.00 \\
\hline OP5.Queue & & 0.00 & \multicolumn{2}{|l|}{ OP5.Queue } & 0.00 \\
\hline OP6.Queue & & 0.07936275 & \multicolumn{2}{|l|}{ OP6.Queue } & 0.00578687 \\
\hline Total Time & & Average & Half Width & $\begin{array}{c}\begin{array}{c}\text { Minimum } \\
\text { Value }\end{array} \\
\end{array}$ & $\begin{array}{l}\text { Maximum } \\
\text { Value }\end{array}$ \\
\hline$\overline{\text { Part 1 }}$ & & 117.17 & (Insufficient) & 50.1605 & 169.61 \\
\hline
\end{tabular}

Fig. 5. Model report on "AS-IS" with the possibility of defective parts reprocessing (2 stage of modeling)

The implementation of the simulation is presented in Fig. 2 when two units of equipment were installed for OP 1 operation helped to obtain a more even load factor of equipment (Fig. 6), to increase the number of processed parts (33 valid parts, 9 parts were re-processed, 1 part has an unrecoverable defect, and the results are not included in reporting Fig. 6). Profit on the production process (according to formula 1) was $\$ 1356.31$. 
The implemented model is the most productive for the processed parts output. However, estimating the additional costs for the equipment and increasing the processed parts output by 18 pieces showed that this model is economically inexpedient.

The model shown in Fig. 3 is of great interest. Changing the parameters entering the production process "Part 2", the maximum load of equipment can be achieved and the output of processed parts "Part 1" and "Part 2" can be optimized. The largest number of the processed parts ("Part 1" - 25 pieces, "Part 2" - 56 pieces) is achieved when "Part 2" is 1 time per 7 minutes (the law of distribution between the parts incoming is exponential).

\begin{tabular}{|c|c|c|c|c|c|}
\hline \multicolumn{6}{|l|}{ Usage } \\
\hline & $\underline{\text { Inst Util }}$ & Num Busy & Num Sched & Num Seized & $\underline{\text { Sched Uti }}$ \\
\hline $\begin{array}{l}\text { Machine } 1 \\
\text { Machine } 2 \\
\text { Machine } 3 \\
\text { Machine } 4 \\
\text { Machine } 5 \\
\text { Machine } 6\end{array}$ & $\begin{array}{l}0,81 \\
0,68 \\
0,50 \\
0,54 \\
0,82 \\
0,93\end{array}$ & $\begin{array}{l}1,62 \\
0,68 \\
0,50 \\
0,54 \\
0,82 \\
0,93\end{array}$ & $\begin{array}{r}2,00 \\
1,00 \\
1,00 \\
1,00 \\
1,00 \\
1,00\end{array}$ & $\begin{array}{r}61,00 \\
59,00 \\
59,00 \\
58,00 \\
57,00 \\
43,00\end{array}$ & $\begin{array}{l}0,81 \\
0,68 \\
0,50 \\
0,54 \\
0,82 \\
0,93\end{array}$ \\
\hline \multicolumn{6}{|l|}{ Cost } \\
\hline & & Busy Cost & Idle & Cost & Usage Cost \\
\hline Machine 1 & & 638.39 & & 60.06 & 0.00 \\
\hline Machine 2 & & 162.85 & & 25.72 & 0.00 \\
\hline Machine 3 & & 99.38 & & 31.95 & 0.00 \\
\hline Machine 4 & & 151.44 & & 44.08 & 0.00 \\
\hline Machine 5 & & 260.58 & & 10.28 & 0.00 \\
\hline Machine 6 & & 221.47 & & 5.71 & 0.00 \\
\hline
\end{tabular}

Fig. 6. Model report "AS-IS" (2nd stage of modeling) with two pieces of equipment Machine 1 installed

The generated report on this model, shown in Fig. 7, estimates the load factor from 1.00 for Machine 1 to 0.41 - for Machine 5.

\section{Usage}

\begin{tabular}{lrrrr}
\hline & Inst Util & Num Busy & Num Sched & Num Seized \\
Machine 1 & 1,00 & 1,00 & 1,00 & 37,00 \\
Machine 2 & 0,98 & 0,98 & 1,00 & 86,00 \\
Machine 3 & 0,71 & 0,71 & 1,00 & 85,00 \\
Machine 4 & 0,78 & 0,78 & 1,00 & 84,00 \\
Machine 5 & 0,41 & 0,41 & 1,00 & 28,00 \\
Machine 6 & 0,60 & 0,60 & 1,00 & 28,00
\end{tabular}

Cost

\begin{tabular}{|c|c|c|c|c|}
\hline & Busy Cost & \multicolumn{2}{|c|}{ Idle Cost } & \\
\hline Machine 1 & 391.01 & \multicolumn{2}{|c|}{0.00} & \\
\hline Machine 2 & 234.94 & \multicolumn{2}{|c|}{1.42} & \\
\hline Machine 3 & 141.76 & \multirow{2}{*}{\multicolumn{2}{|c|}{$\begin{array}{l}18.42 \\
20.86\end{array}$}} & \\
\hline Machine 4 & 217.74 & & & \\
\hline Machine 5 & 129.77 & \multicolumn{2}{|c|}{33.29} & \\
\hline Machine 6 & 144.67 & \multicolumn{2}{|c|}{31.78} & \\
\hline Time & \multicolumn{3}{|c|}{ Other } & \\
\hline Waiting Time & \multicolumn{3}{|c|}{ Number Waiting } & Average \\
\hline OP1.Queue & 71.9111 & \multicolumn{2}{|l|}{ OP1.Queue } & 8.6087 \\
\hline OP2.Queue & 26.0140 & \multicolumn{2}{|l|}{ OP2. Queue } & 6.4255 \\
\hline OP3.Queue & 0.00 & \multicolumn{2}{|l|}{ OP3.Queue } & 0.00 \\
\hline OP4.Queue & 0.06761115 & \multicolumn{2}{|l|}{ OP4.Queue } & 0.01183195 \\
\hline OP5.Queue & 0.2767 & \multicolumn{2}{|l|}{ OP5.Queue } & 0.01614183 \\
\hline OP6.Queue & 4.1591 & \multicolumn{2}{|l|}{ OP6.Queue } & 0.2426 \\
\hline Total Time & Average & Half Width & $\begin{array}{c}\text { Minimum } \\
\text { Value }\end{array}$ & $\begin{array}{c}\text { Maximum } \\
\text { Value }\end{array}$ \\
\hline$\overline{\text { Part 1 }}$ & 122.89 & (Insufficient) & 55.5407 & 232.70 \\
\hline Part 2 & 40.6730 & (Insufficient) & 13.1811 & 99.44 \\
\hline
\end{tabular}

Fig. 7. Model report "TO-BE"
In general, the load factor is more uniform for the model than for the models discussed above. Machine 1 and Machine 2 are the most overloaded. The average waiting time for processing details is 71.9111 and 26.0140 minutes, and the average number of items in the queue was 8.6087 and 6.4255 respectively. The average length of parts, remaining in the production processing process, was 122.89 minutes for "Part 1", and 40.6730 minutes - for "Part 2". The profit on the production process (according to formula 1) was \$ 1154.12.

\section{CONCLUSION}

A simulation model of the production process was developed within the framework of the discrete-event approach. As a result of modeling, having considered various models of the production process organization, the following was established: the machines load, the number of parts produced, the average length of parts in the production process, the average number of parts in the queue, profits and losses in the production process.

The obtained results of simulating will organize an economically justified production process - two-subject ("Part 1 " and "Part 2") production line with an increase in profit 1.45 times. Thus, the system of simulation allows one to analyze quickly production processes and to make economically sound decisions. It is especially true for enterprises with a rapidly changing range of goods and small series production output.

\section{References}

[1] R. Shannon, Systems Simulation the Art and Science, Mir, Moscow, 1978.

[2] D.J. Medeiros, E.F. Watson, J.S. Carson eds., "Introduction to the art and science of simulation Robert E. Shannon," Proceedings of the 1998 Winter Simulation Conference Texas A\&M University College Station, Texas 77843-3131, U.S.A., pp. 7-14.

[3] E.E. Alyoshina, A.A. Salomatin, E.I. Yablochnikov, "Creation of a simulation model of an assembly line using the DELMIA system." Scientific and Technical Herald of St. Petersburg State University information technology, mechanics and optics, vol. 71, 2011, pp. 5053.

[4] W. Nyemba, C. Mbohwa, "Modelling, simulation and optimization of the materials flow of a multi-product assembling plant," 14th Global Conference on Sustainable Manufacturing, GCSM 3-5 October 2016, Procedia Manufacturing vol. 8, 2017, pp.59-66.

[5] O.S. Vysochina, V.N. Danich, V.P. Parkhomenko, "Modeling of production processes in an industrial enterprise using the ARENA simulation system," https://library.ru/download/elibrary_19436402_ 55899178.pdf/

[6] C.Oprea, E. Rosca, A. Popa et al, "The quality of service in passenger transport terminals," IOP Conference Series: Materials Science and Engineering. Vol.161 (2016) pp. 1-9.

[7] Y. Yan-mei, L. Xin-jun "Optimization of Ex-warehouse and Warehousing for Logistics Park Based on Computer Simulation," 3rd International Conference on Materials Engineering, Manufacturing Technology and Control (ICMEMTC 2016), pp. 1331-1337.

[8] Kozhemyakina O P, Guseva E N 2015 The use of the simulation to improve the activities of the construction company http://technology.snauka.ru/2015/06/7094/

[9] X. Li, K. Pan, "Simulation and Optimization of M-commerce Steel Logistics System Based on Arena "Advances in Economics, Business and Management Research, vol. 31, MSMI 2017, pp.28 - 32.

[10] K.D. Rao, "Modeling, Simulation and Control of the Semi Active Suspension System for Automobiles under MATLAB Simulink using 
PID Controller," https://www.sciencedirect.com/science/article/pii/ $\underline{\text { S1474667016327501/ }}$

[11] W. D. Kelton, R. P. Sadowsky and D.T. Sturrock, Simulation with Arena, 3rd ed., New York: The McGraw-Hill Companies, 2004. 